\title{
Pulmonary rehabilitation focusing on the regulation of respiratory movement can improve prognosis of severe patients with COVID-19
}

\author{
Jiaolin Sun ${ }^{1} \wedge$, Jia Liu ${ }^{1}$, Hong $\mathrm{Li}^{1}$, Cuixia Shang ${ }^{2}$, Tingting $\mathrm{Li}^{1}$, Wenwen $\mathrm{Ji}^{1}$, Jing $\mathrm{Wu}^{3}, \mathrm{Xu} \mathrm{Han}{ }^{4}$, \\ Zhihong Shi ${ }^{1}$
}

${ }^{1}$ Department of Respiratory and Critical Care Medicine, The First Affiliated Hospital of Xi'an Jiaotong University, Xi'an, China; ${ }^{2}$ Rehabilitation Department, The First Affiliated Hospital of Xi'an Jiaotong University, Xi'an, China; ${ }^{3}$ Oncological Surgery, The First Affiliated Hospital of Xi'an Jiaotong University, Xi'an, China; ${ }^{4}$ Infectious Disease Department, The First Affiliated Hospital of Xi'an Jiaotong University, Xi'an, China Contributions: (I) Conception and design: H Li; (II) Administrative support: C Shang; (III) Provision of study materials or patients: J Sun, J Wu, X Han; (IV) Collection and assembly of data: T Li, W Ji; (V) Data analysis and interpretation: J Sun, J Liu; (VI) Manuscript writing: All authors; (VII) Final approval of manuscript: All authors.

Correspondence to: Dr. Zhihong Shi. No.277 Yanta Road, Yanta District, Xi’an 710061, China. Email: docszh@163.com.

Background: Since the coronavirus disease 2019 (COVID-19) emerged in Wuhan, China, it has become a global public health emergency. Besides conventional care, pulmonary rehabilitation (PR) is an equally important treatment for patients with COVID-19 suffering from respiratory, physical and psychological disease. The aim of this study is to investigate the role of PR on the inpatients with severe COVID-19.

Methods: This study was a self-pre- and post-control prospective clinical trial, which totally recruited 31 inpatients confirmed COVID-19 by RT-PCR. They were performed 3-week PR. The demographic data, medical records, symptoms, laboratory findings and chest computed tomographic (CT) scans of patients were collected at baseline. The effect of PR was assessed by questionnaires before PR as well as after 2- and 3-week PR.

Results: After 3-week PR and treatment, neutrophil percentage decreased, while lymphocyte percentage and lymphocyte count increased (before vs. 2 weeks after $\mathrm{PR}$ respectively: $\mathrm{P}=0.001 ; \mathrm{P}=0.001 ; \mathrm{P}<0.0001$ ). Besides, CRP and procalcitonin reduced significantly (before vs. after respectively: $\mathrm{P}<0.0001 ; \mathrm{P}=0.023$ ). Patients' oxygen intake decreased and oxygen saturation increased significantly. Meanwhile, PR relieved the patients' symptoms of cough and dyspnea, improved the patients' self-care ability, physical fitness and mental state significantly. Activities of daily living (ADL) score increased and Modified Medical Research Council Dyspnea Scale (mMRC) decreased after PR.

Conclusions: PR can relieve symptoms, enhance health-related quality of life, improve respiratory muscle function and alleviate disease-related anxiety and depression of severe patients with COVID-19. PR should be provided throughout the diseases management process, regardless of whether the patient is hospitalized or at home.

Keywords! Coronavirus disease 2019 (COVID-19); pulmonary rehabilitation; symptoms; activities of daily living (ADL)

Submitted Oct 15, 2020. Accepted for publication Feb 25, 2021.

doi: 10.21037/apm-20-2014

View this article at: http://dx.doi.org/10.21037/apm-20-2014

$\wedge$ ORCID: 0000-0003-3555-9341. 


\section{Introduction}

Since the coronavirus disease 2019 (COVID-19) emerged in Wuhan, China, in December, 2019 (1), as of 7 July, 2020, a total of 11,653,925 laboratory-confirmed cases has been documented globally (2). It has spread worldwide and has become a global public health emergency. The common initial symptoms of COVID-19 are fever, cough, fatigue, anorexia, myalgia and diarrhea (3). Lung is the most affected organ by COVID-19, with pathologies that contain diffuse alveolar epithelium destruction, capillary damage/ bleeding, hyaline membrane formation, alveolar septal fibrous proliferation, and pulmonary consolidation (4). Some severe patients may have long-term impairment and dysfunctions, including pulmonary fibrosis, acute respiratory dyspnea syndrome (ARDS), heart, liver, kidney, nerve and immune system (5). Besides conventional care, such as symptomatic and antiviral therapy, pulmonary rehabilitation (PR) is equally important to the treatment for patients with COVID-19 suffering from respiratory, physical and psychological disease (6).

$\mathrm{PR}$, defined as a comprehensive non-pharmacological intervention, is generally quite effective in patients with chronic obstructive pulmonary disease (COPD) and interstitial lung disease $(7,8)$, and has also been regarded as one of the most important interventions for patients with COPD (9). PR has many benefits including improving respiratory function, exercise endurance, self-care in daily living activities, as well as psychological support, etc. (10). It has been suggested that physical training can improve both the cardiorespiratory and musculoskeletal performances in patients with severe acute respiratory (SARS) (11). Patients with COVID-19 may have some residual fibrotic lesions in the lungs following current treatment and discharge protocols, which can affect the patient's respiratory function (12). Therefore, the evidence of PR for patients with SARS provided strong support and reference for the development of PR for patients with COVID-19.

Rehabilitation specialists in China have developed practical and feasible PR guidelines for patients with COVID-19 (13). With the promulgation of PR guidelines, $\mathrm{PR}$ has been used as one of the therapeutic methods for inpatient and discharged patients with COVID-19. Based on the guidelines, we applied "breathing method" as the core of PR for inpatients with COVID-19. Up to now, few studies have been conducted on the improvement of symptoms in inpatients with COVID-19 receiving PR therapy. The purpose of this study is to investigate into the effect of a 3-week PR program on the inpatients with COVID-19 who were severe at the time of admission but had stabilized after standard treatment. We present the following article in accordance with the TREND reporting checklist (available at http://dx.doi.org/10.21037/apm-20-2014).

\section{Methods}

\section{Participants}

Participants with confirmed COVID-19 by RT-PCR (14) were recruited from Renmin Hospital of Wuhan University from January $30^{\text {th }}, 2020$ to March $3^{\text {rd }}, 2020$. Renmin Hospital of Wuhan University, located in Wuhan, Hubei Province, the endemic areas of COVID-19, is one of the major tertiary hospitals assigned by the government for the treatments for severe patients with COVID-19. The definitions of severe patients are: respiratory rate of more than $30 /$ minute or an oxygen saturation $\left(\mathrm{SaO}_{2}\right)$ of $93 \%$ or less when they were breathing ambient air or a ratio of the partial pressure of oxygen $\left(\mathrm{PaO}_{2}\right)$ to the fraction of inspired oxygen $\left(\mathrm{FiO}_{2}\right)\left(\mathrm{PaO}_{2}: \mathrm{FiO}_{2}\right)$ at or below $300 \mathrm{mmHg}(15)$. We enrolled 31 patients (19 males and 12 females), who accepted standardized treatment according to the Diagnosis and Treatment Guideline for New Coronavirus Pneumonia (6) for 2 weeks and can perform PR after assessment. Exclusion criteria: (I) patients with a high risk of mortality; (II) patients with dementia, tumor or metastatic cancer, and acute myocardial infarction/acute coronary syndrome.

Oral consent was obtained from patients or patients' relatives. Informed consents were obtained for all involved subjects in accordance with the Institutional Review Board (IRB) of the First Affiliated Hospital of Xi'an Jiaotong University (No: XJTU1AF2021LSK-037). The study conformed to the provisions of the Declaration of Helsinki (as revised in 2013).

\section{Study design}

This study is a before-after self-control study. The contents of PR included (I) breathing exercise; (II) respiratory muscle training; (III) stretching training; (IV) psychotherapy. Patients can perform PR ( 2 sessions per day for 3 weeks) in the isolation ward by video teaching (16).

\section{Breathing method exercise (3-5-6 breathing)}

It can be performed in a seated, bedside seated or a standing position. Each breathing cycle consists of deep inhalation for 3 seconds-holding breath for 3-5 seconds, and slow exhalation for about 6 seconds; $3-4$ respiratory cycles in 

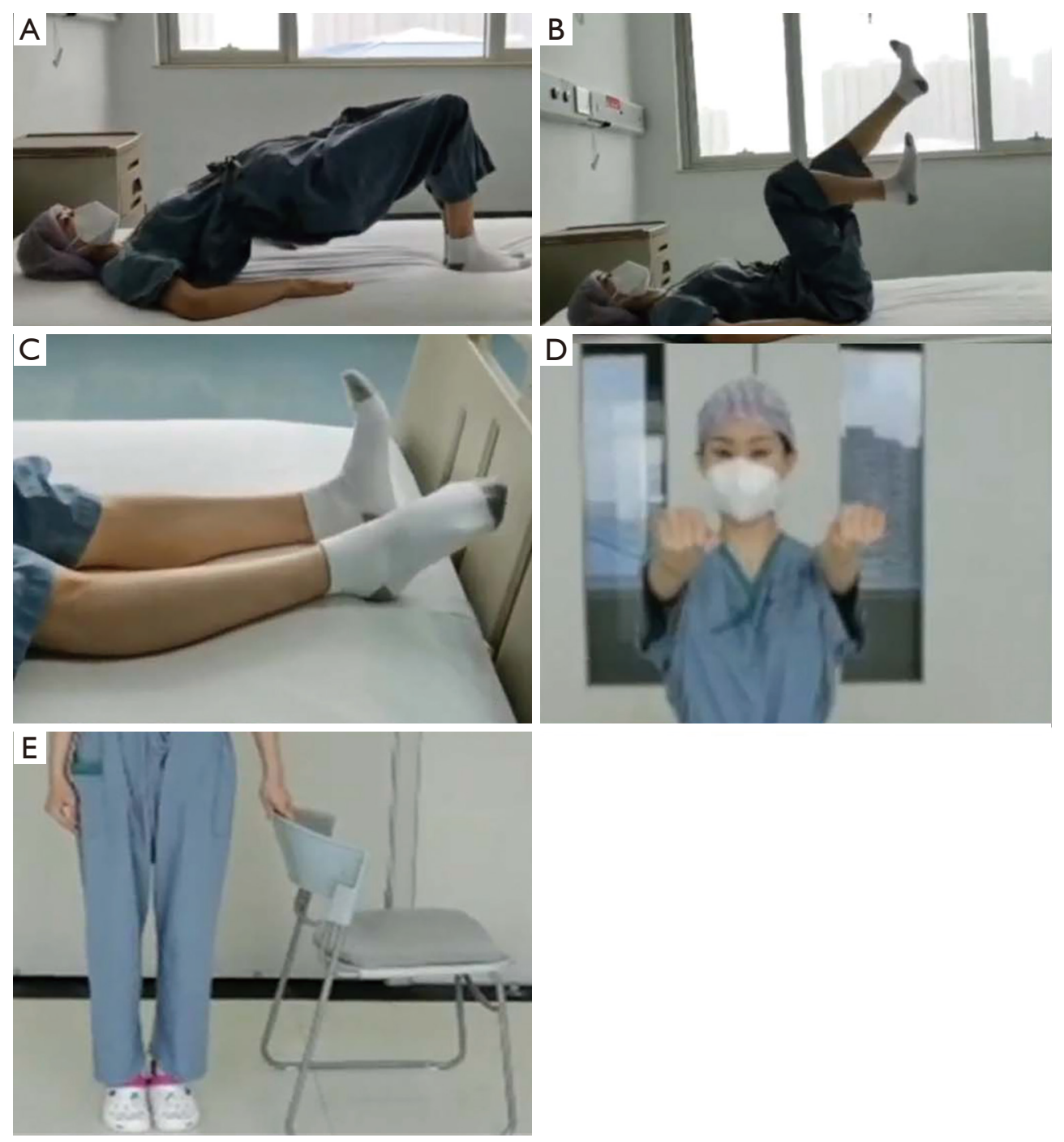

Figure 1 The pose in PR. (A) Bridge exercise; (B) air pedal; (C) ankle pump; (D) grasping; (E) tiptoeing.

each set; patients can rest for 30-60 seconds between each set depending on shortness of breath.

\section{Respiratory muscle training (twice a day)}

Relax the whole body in the right lateral decubitus position and inhale slowly to let the gas fully into the left lung, then exhale. Inhale and exhale alternately for 15 minutes. Then change to the left lateral decubitus position. Breathe calmly, then bridge exercise (Figure 1A), alternating straight leg, air pedal (Figure 1B) and ankle pump (Figure 1C) in supine position (17).

\section{Stretching training (twice a day)}

(I) Upper limbs exercise: upward lift, lateral lift, abduction, chest enlargement and grasping (Figure 1D), which were designed to improve the function of muscle groups around the shoulders, upper arms and forearms. (II) Lower limb exercise: lifting, kicking, tiptoeing (Figure $1 E$ ) and stepping, for building muscle strength in the lower extremities. Each action lasts for 5 seconds, repeat the whole set 2-3 times each time. All exercises can be performed in lying position, sitting position and standing position coordinated with breathing regulation (18).

\section{Psychotherapy}

Patients listen to light music for 20 minutes per day, and a professional psychiatrist uses a mobile phone to perform psychological intervention (19). 


\section{Safety procedures}

In the process of $\mathrm{PR}$, patients should act according to their ability and make gradual progress. Nurses need to closely monitor patients' vital signs, and the patients' oxygen saturation should be greater than $93 \%$ and heart rate should be less than 120 beats/minute during PR. If patients feel uncomfortable during PR, such as palpitation, sweating, shortness of breath, they need to stop PR. Additionally, patients who needed oxygen therapy could do it in bed or at bedside.

\section{Data collection and assessment}

\section{Baseline}

The demographic data, medical records, symptoms, laboratory findings and chest computed tomographic (CT) scans of patients were collected at baseline.

\section{Primary outcome measures}

Respiratory symptoms; secondary outcome measures: exercise endurance, activities of daily living (ADL) score, blood oxygen saturation $\left(\mathrm{SaO}_{2} \%\right)$, and oxygen intake. We prospectively collected patients' outcomes on three different time points: first at admission, second two weeks after they began PR, then three weeks after they began PR.

\section{Assessment of respiratory symptoms}

The respiratory symptoms included cough, sputum and dyspnea, which was assessed by questionnaires. Dyspnea was evaluated using the modified Medical Research Council (mMRC) dyspnea scale (20). If $\mathrm{mMRC}$ score was equal to or more than 2, exertional dyspnea was identified.

Exercise tolerance, which was an assessment included whether you can elevate leg in bed and stand and sit by yourself.

ADL assessments included whether they can put on their own shoes, wear clothes and go to the toilet. Functional status was subjectively assessed by interviewers using ADL score (the total score ranges from 0 to 100) (21), and high scores indicate strong self-care ability.

Additionally, $\mathrm{SaO}_{2} \%$, oxygen intake, diet and sleep were recorded.

\section{Statistical analysis}

The data were analyzed using SPSS version 26 statistical software. Baseline characteristics were presented as count and percentage for categorical data, mean \pm standard deviation (SD) for normally distributed continuous data and median (inter quartile range) for continuous data of skewed distribution. As appropriate, before and after PR, comparisons were carried out using paired samples- $t$ test when the data were normally distributed and using the Maan-Whitney test when they were not, while categorical data were tested using the chi-square test. $\mathrm{A} P<0.05$ or $\mathrm{P}<0.01$ was considered statistically significant.

\section{Results}

\section{Demographic and clinical characteristics of patients}

We enrolled 31 patients (19 males, 12 females) with COVID-19 from Renmin Hospital of Wuhan University from January $30^{\text {th }}, 2020$ to March $3^{\text {rd }}$, 2020. The demographic and clinical characteristics of patients were shown in Table 1. Mean age was $60.39 \pm 10.20$ years and all enrolled patients were never smoked. Among them, 22.58\% of patients once accepted PR. In the first 3 days after PR treatment, 21 patients had side effects of muscle soreness and fatigue. However, with regular rehabilitation, side effects disappeared within 1 week.

\section{Laboratory findings of patients before and after PR and treatment}

Variations in laboratory findings of patients before and after PR and treatment were listed in Table 2. Comparing of inflammatory markers in the blood, we found neutrophil percentage decreased, lymphocyte percentage and lymphocyte count increased after 2-week PR. While, CRP and procalcitonin reduced after 2-week PR. By reflecting the results of nutrient level in vivo, we found that $\mathrm{RBC}$ and HGB didn't rise until 3 weeks after PR, while ALB and TCHO elevated after 2-week PR.

\section{Assessment of symptoms and results of questionnaires before PR and treatment and after 2- and 3-week PR}

Table 3 showed the difference of symptoms and the results of questionnaires before and after PR. We can see that shortness breath, cough and sputum production relieved significantly after PR, while the number of fatigue patients increased $(\mathrm{P}<0.0001)$. The baseline prevalence for dry cough, productive cough, and dyspnea was $67.74 \%$, $54.84 \%$, and $51.61 \%$, respectively, which all decreased pronouncedly over time. After 2 -week PR, the prevalence rate was $6.9 \%$ in dry cough, $20.69 \%$ in productive cough, 
Table 1 Demographic and clinical characteristics of patients

\begin{tabular}{lc}
\hline Characteristics & Patients (N=31) \\
\hline Age (years) & $60.39 \pm 10.20$ \\
Male sex, No. (\%) & $19(61.29)$ \\
Smoking history, No. (\%) & \\
Never smoked & $31(100.00)$ \\
Had a history of PR & $7(22.58)$ \\
Symptoms on admission, No. (\%) & \\
Fever & $23(74.19)$ \\
Cough & $22(70.97)$ \\
Fatigue & $1(3.23)$ \\
Shortness breath & $12(38.71)$ \\
Diarrhea & $2(6.45)$ \\
Sputum production & $4(12.90)$ \\
Coexisting disorder, No. (\%) & $21(67.74)$ \\
Diabetes & $1(3.23)$ \\
Hypertension & $2(6(6.45)$ \\
Hepatitis B infection & $2(6.45 .45)$ \\
Cancer & \\
Chronic renal disease & \\
Coronary heart disease & \\
Tuberculosis & \\
Don't have coexisting disorder & \\
\hline
\end{tabular}

and only $31.03 \%$ of patients reported dyspnea as a remained symptom. After 3-week PR, none had sputum and fewer felt fatigue or shortness breathe or palpitate and all patients can wear clothes or shoes or go to the toilet by themselves. Those patients only felt fatigue or shortness breathe when walked after 3-week PR. As the progresses of PR, the patients' sleep and diet have improved.

\section{Improvement of hypoxemia and ADL score before and after $P R$}

As shown in Figure 2, mMRC both decreased after 2- and 3-week PR. Meanwhile, the patients' oxygen intake decreased. $\mathrm{SpO}_{2}$ increased after 2- and 3-week PR. The patients' ADL score also improved after PR. There was no significant difference in $\mathrm{mMRC}$, oxygen intake, $\mathrm{SpO}_{2}$ and ADL between 2 and 3 weeks after PR.

\section{Discussion}

COVID-19 is a highly infectious respiratory disease and the initial symptoms of patients with COVID-19 were fever, cough and dyspnea (22). There are currently no effective treatments or vaccines other than meticulous supportive care, so it is necessary to find more measures to deal with this pneumonia. With the accumulation of experience in the treatment, PR is crucial for severe and critically ill patients who have respiratory, physical, and psychological dysfunction.

Veronica illustrated that increased production of inflammatory cytokines occurred in COVID-19 patients, especially in severe patients, whose the inflammatory response is enhanced (23). Through routine treatment and PR, we found that the count and percentage of patients' lymphocytes increased, and inflammatory response was weakened. The results are similar to the findings of Do et al. and Davidson. Davidson et al. found a reduction in plasma IL-6, IL-8, CRP levels and Davidson indicated that CD8+T lymphocytes increased after PR (24), which proved that the anti-inflammatory response to exercise in patients with COPD. Because the muscle fibers appear to produce antiinflammatory cytokines, which can inhibit the production of the inflammatory cytokine (25). In healthy individuals, the proinflammatory response is balanced by the antiinflammatory response after a vigorous aerobic exercise (26). Undoubtedly, with regular treatment and improved symptoms, the patients' inflammatory response will be reduced. So PR can be used as an adjunct therapy to reduce the COVID-19 patients' inflammatory response.

Nanshan Zhong's team revealed that in discharged survivors with COVID-19, impairment of diffusion capacity is the most common abnormality of lung function followed by restrictive ventilatory defect, which were both associated with the severity of the disease (27). Sonnweber's research evaluated data on 145 patients with COVID-19 at 60 and 100 days after confirmed diagnosis, and found that $41 \%$ of all subjects exhibited persistent symptoms 100 days after COVID-19 onset, with dyspnea being most frequent $(36 \%)$. Accordingly, patients still displayed an impaired lung function, with a reduced diffusing capacity in $21 \%$ of 
Table 2 Laboratory findings of patients before and after PR and treatment

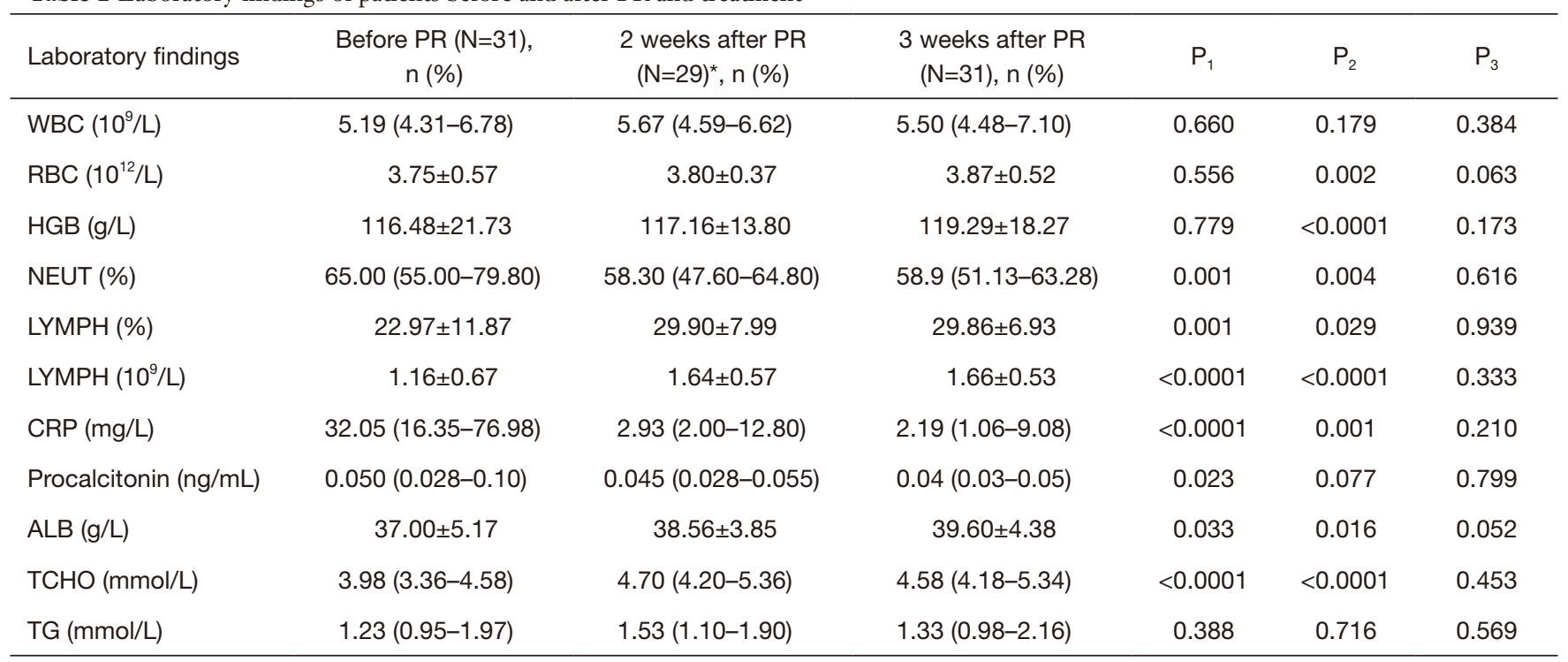

$\mathrm{P}_{1}, 2$ weeks after PR vs. before PR; $\mathrm{P}_{2}, 3$ weeks after PR vs. before PR; $\mathrm{P}_{3}, 3$ weeks after PR vs. 2 weeks after PR. ${ }^{*}$, two patients didn't record data 2 weeks after PR. WBC, white blood cell; RBC, red blood cell; HGB, hemoglobin; PLT, platelet; NEUT, neutrophil; LYMPH, lymphocyte; CRP, C-reactive protein; ALB, albumin; TCHO, total cholesterol; TG, triglycerides.

the cohort being the most prominent finding (28). In our study, after two weeks of PR, the patients' mMRC score and oxygen intake decreased and $\mathrm{SpO}_{2}$ increased significantly. Meanwhile, PR relieved the patients' symptoms of cough and dyspnea, and improved the patients' self-care ability, physical fitness and mental state. We can conclude that PR does have an impact on the remission of symptoms.

$\mathrm{PR}$ has been shown to improve gas change and reverse pathological progression in many respiratory diseases. Because the patients' lung volume and lung compliance were reduced, resulting in shallow and fast breathing and causing restrictive ventilation disorders. Besides, infection led to a reduction in the diffuse area of lung, an increase in shunt and a reduction in arterial oxygen partial pressure, which caused gas exchange dysfunction (29). According to the pathophysiological changes in lung, we applied "breathing method" (3-5-6 breathing), which elevated ventilation and gas exchange function, as the core of $\mathrm{PR}$ for inpatients with COVID-19. As a result, tidal volume increased, diaphragmatic muscle capacity enhanced and lung compliance improved by the adjustment of respiratory rhythm. On the one hand, prolonging breathing cycle time such as deep breathing and labial reduction breathing improved the restrictive ventilatory defect. On the other hand, increasing breath retention time in alveoli by breathholding was to improve gas exchange function and effective alleviate hypoxemia and local atelectasis. Therefore, the patients' maximum oxygen consumption increased dramatically, so that shortness of breath was relieved and mobility and quality of life was improved (30).

Symptoms, especially dyspnea, which caused reductions in ADL, and this situation leads to dependence and disability (31). With the symptoms improved, the patients' ability to take care of themselves can also been restored. Likewise, Zha et al. applied Chinese martial art Eightsection Brocade to patients with COVID-19 and found the pronouncedly improved remission rate in respiratory symptoms (32). It can be implied that RP was considered to be capable of inducing positive effects on patients' respiratory muscles through diaphragm breathing exercise and lip puckering breathing exercise. Abdullahi showed the patients with COVID-10 after discharge, chest physiotherapy in the form of respiratory muscle training, cough exercise, diaphragmatic training, stretching exercise have an increase in lung function, diffusing lung capacity for carbon monoxide, endurance, and quality of life, and a reduction in anxiety and depression symptoms (33). LópezLópez discovered the integrated physical therapy focusing on pulmonary function training and active upper limb exercise improved physical and functional performance in elderly patients with pneumonia (34). These results indicated that the upper limb movement enhanced the strength of the upper limb muscles by synchronous lifting, lateral lifting, chest expansion, and grasping movements, 
Table 3 Assessment of symptoms and results of questionnaires before and 2 and 3 weeks after PR and treatment

\begin{tabular}{|c|c|c|c|c|c|c|}
\hline Items & $\begin{array}{c}\text { Before PR }(\mathrm{N}=31) \\
\mathrm{n}(\%)\end{array}$ & $\begin{array}{c}2 \text { weeks after PR } \\
(\mathrm{N}=29)^{\star}, \mathrm{n}(\%)\end{array}$ & $\begin{array}{c}3 \text { weeks after PR } \\
(\mathrm{N}=31), \mathrm{n}(\%)\end{array}$ & $P_{1}$ & $\mathrm{P}_{2}$ & $P_{3}$ \\
\hline \multicolumn{7}{|l|}{ Current symptoms } \\
\hline Fatigue & $10(32.26)$ & $18(62.07)$ & $28(90.32)$ & 0.013 & 0.003 & 0.031 \\
\hline Shortness breath & $16(51.61)$ & $9(31.03)$ & $1(3.23)$ & 0.016 & $<0.0001$ & 0.008 \\
\hline Effect of cough on life & & & & 0.732 & 0.115 & 0.018 \\
\hline No effect & 15 (48.39) & $7(24.14)$ & $1(3.23)$ & & & \\
\hline Marginal effect & $8(25.81)$ & $22(75.86)$ & 30 (96.77) & & & \\
\hline Whitish sputum & $17(54.84)$ & $6(20.69)$ & 0 & & & \\
\hline \multicolumn{7}{|l|}{ Productive cough } \\
\hline Easy & $6(19.35)$ & $3(10.34)$ & - & & - & - \\
\hline Difficult & $3(9.68)$ & $2(6.90)$ & - & 0.274 & - & - \\
\hline Can't cough phlegm & $8(25.81)$ & $1(3.45)$ & - & & - & - \\
\hline When feel fatigue & & & & 0.057 & 0.301 & 0.011 \\
\hline Walk & 25 (50.65) & 28 (96.55) & $31(100.00)$ & & & \\
\hline No shortness breathe & $1(3.23)$ & 0 & 0 & & & \\
\hline Whether palpitate & & & & 0.001 & $<0.0001$ & 0.057 \\
\hline Never & $10(32.26)$ & $22(75.86)$ & 29 (93.55) & & & \\
\hline Seldom & 20 (64.52) & $7(24.14)$ & $2(6.45)$ & & & \\
\hline Usually & $1(3.23)$ & 0 & 0 & & & \\
\hline Elevate leg in bed & & & & 0.189 & 0.040 & 0.301 \\
\hline Can & 27 (87.10) & 28 (96.55) & $31(100.00)$ & & & \\
\hline Can't & $4(12.90)$ & $1(3.45)$ & 0 & & & \\
\hline Sand and sit by yourself & & & & 0.189 & 0.040 & 0.301 \\
\hline Can & 27 (87.19) & $28(96.55)$ & $31(100.00)$ & & & \\
\hline Can't & $4(12.90)$ & $1(3.45)$ & 0 & & & \\
\hline
\end{tabular}

Table 3 (continued) 
Table 3 (continued)

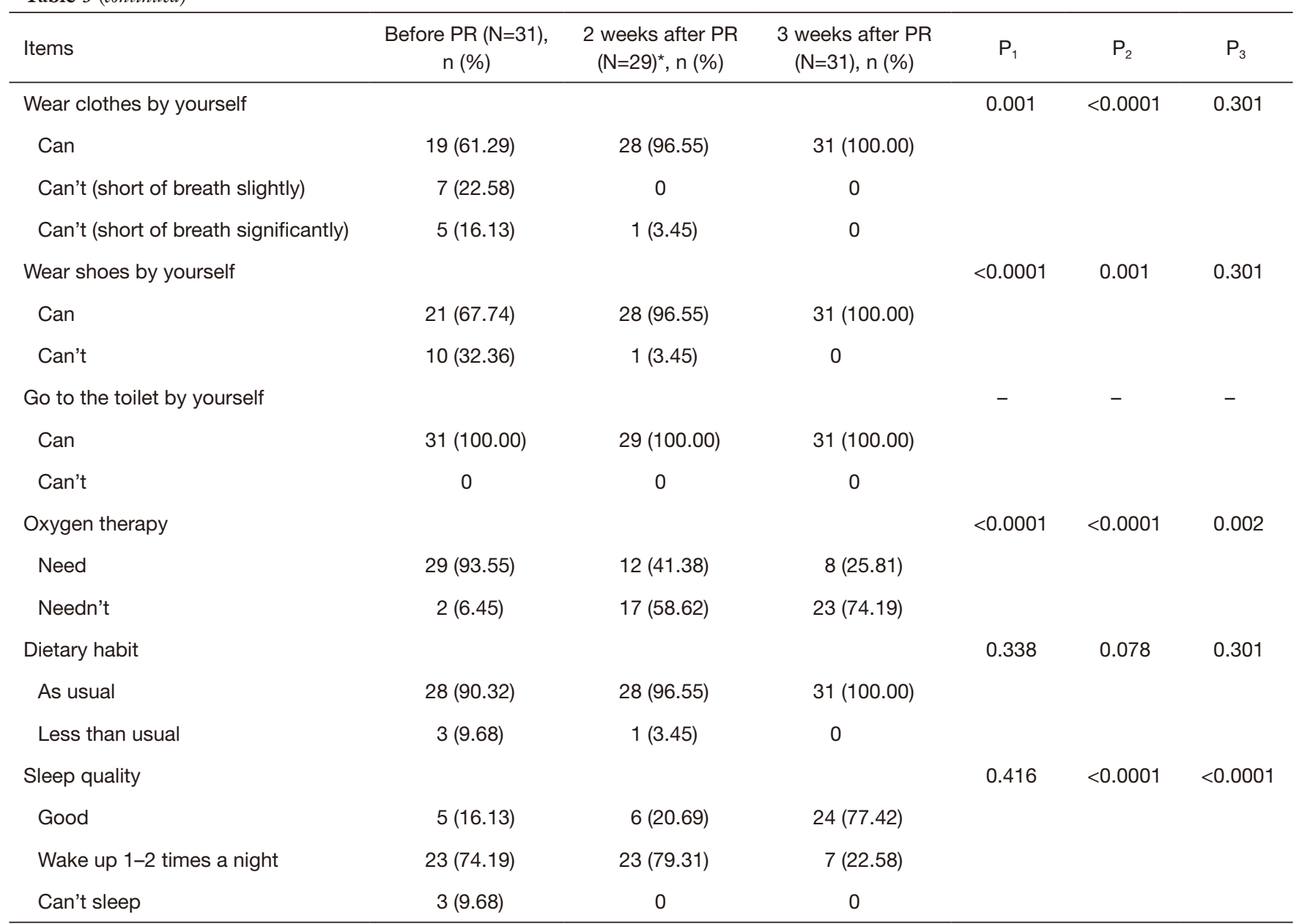

$\mathrm{P}_{1}, 2$ weeks after PR vs. before PR; $\mathrm{P}_{2}, 3$ weeks after PR vs. before PR; $\mathrm{P}_{3}, 3$ weeks after PR vs. 2 weeks after PR. *, two patients didn't record data 2 weeks after $P R$.

and the functions of the muscle groups around the shoulders, upper arms and forearms recovered gradually. Lower limb movement can enhance the strength of lower limb muscles and the stability of the body gradually, promote blood circulation of lower limb, and restore the function of lower limb muscle groups through leg lifting, kicking, bouncing and stepping. Thus, combined with our data, it is suggested that stretching training can increase muscle volume and myoglobin of the patients, resulting in an enhanced ability of the respiratory and circulatory system to coordinate work.

Severe patients with COVID-19 may suffer a higher degree of psychological disorders, such as anxiety, depression, insomnia and anorexic (35). A network platform with doctor-patient participation, psychological assessment, intervention and follow-up were established to adjust patients' psychological state and restore confidence in fighting against COVID-19. Most patients had a good sleep and the diet returned to the normal level so that patients can take in enough nutrition.

To our knowledge, there have been few studies on symptom improvement in hospitalized COVID-19 patients treated with PR. So we performed PR on severe patients with COVID-19 who had received 2 weeks of standardized treatment and were able to undergo PR after assessment. The content of PR we did was not only limited to respiratory exercise, but also included muscle strength training and psychological intervention.

This study has several limitations. In order to prevent infection, we used the improvement of symptom instead of pulmonary function test to evaluate the outcomes of PR. In addition, this is a single center study, which make our 

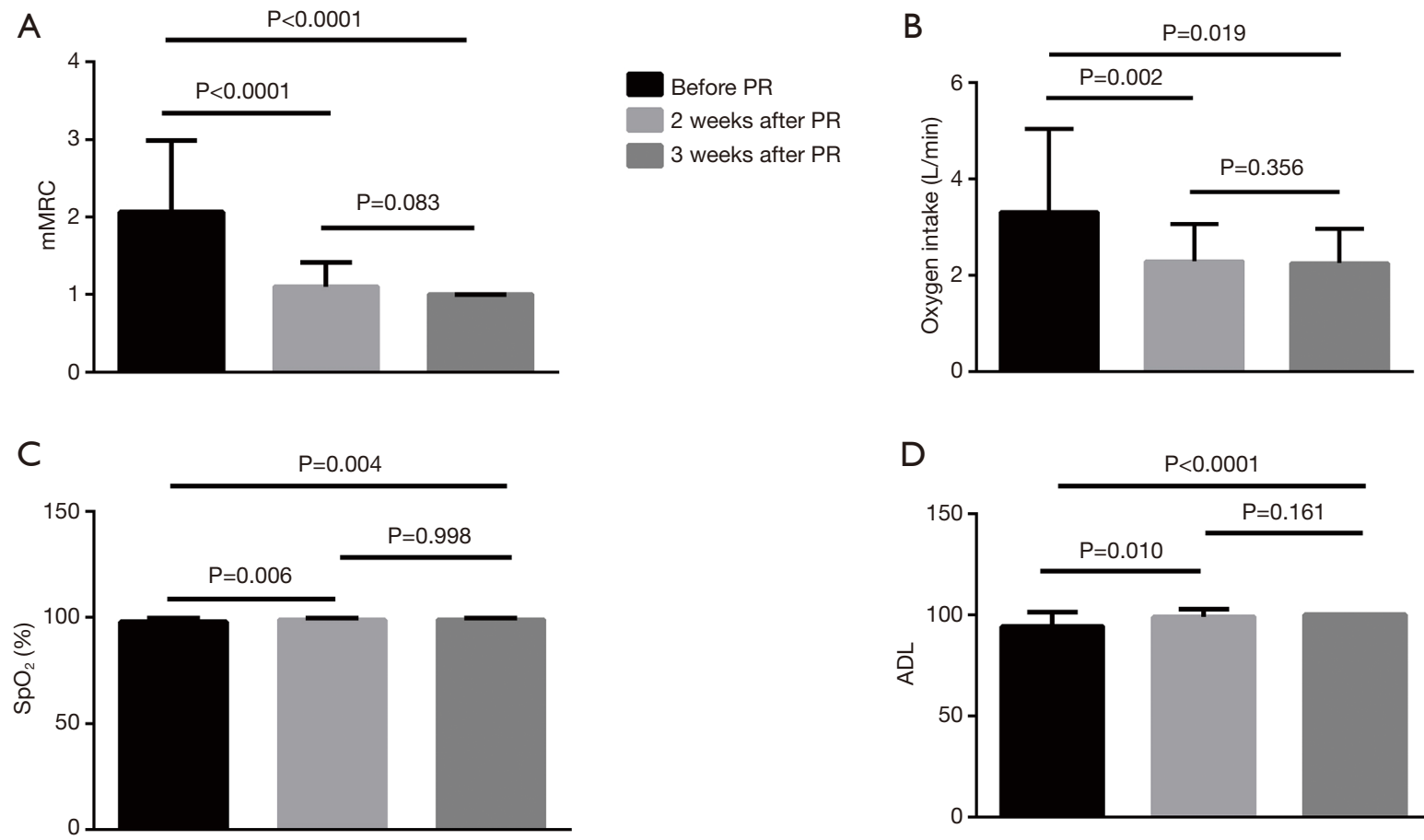

Before PR 2 weeks after $P R$ 3 weeks after PR

Figure 2 Improvement of hypoxemia and ADL score before and after PR. mMRC both decreased after 2- and 3-week PR (respectively: before vs. 2-week PR: $2.07 \pm 0.92$ vs. $1.10 \pm 0.31, \mathrm{P}<0.0001$; before vs. 3-week PR: $2.07 \pm 0.92$ vs. $1.00 \pm 0.01, \mathrm{P}<0.0001)$. While, the patients' oxygen intake decreased (respectively: before $v s .2$-week PR: 3.35 \pm 1.11 vs. $2.29 \pm 0.77, \mathrm{P}=0.002$; before $v s .3$-week PR: $3.35 \pm 1.11$ vs. $2.25 \pm$ 0.71, $\mathrm{P}=0.019$ ). $\mathrm{SpO}_{2}$ both increased after 2- and 3-week PR (respectively: before vs. 2-week PR: 97.88 \pm 1.99 vs. 98.88 $\pm 0.83, \mathrm{P}=0.006$; before vs. 3-week PR: $97.88 \pm 1.99$ vs. $98.89 \pm 0.78, \mathrm{P}=0.004)$. The patients' ADL score also improved after PR (respectively: before vs. 2-week PR: 95.00 \pm 6.68 vs. $98.97 \pm 3.87, \mathrm{P}=0.010$; before vs. 3 -week PR: $95.00 \pm 6.68$ vs. $100.00 \pm 0.00, \mathrm{P}<0.0001)$. ADL, activities of daily living; PR, pulmonary rehabilitation; mMRC, Modified Medical Research Council Dyspnea Scale.

sample size small. To address these limitations, a further double-blind study with a large sample size at multiple centers was required.

\section{Conclusions}

In conclusion, PR can ameliorate symptoms, enhance health-related quality of life, improve respiratory muscle function and alleviate disease-related anxiety and depression of severe patients with COVID-19. PR is a process of restoring physical function slowly, promoting respiratory rehabilitation and relieving emotions, which is of great significance to the prognosis of diseases. PR should be provided throughout the diseases management process, regardless of whether the patient is hospitalized or at home.

\section{Acknowledgments}

We thank the doctors and nurses of Renmin Hospital of
Wuhan University, who assisted us during the epidemic of COVID-19. And we are grateful to many people who donated masks and protective equipment anonymously.

Funding: None.

\section{Footnote}

Reporting Checklist: The authors have completed the TREND reporting checklist. Available at http://dx.doi. org/10.21037/apm-20-2014

Data Sharing Statement: Available at http://dx.doi. org/10.21037/apm-20-2014

Peer Review File: Available at http://dx.doi.org/10.21037/ apm-20-2014

Conflicts of Interest: All authors have completed the ICMJE uniform disclosure form (available at http://dx.doi. 
org/10.21037/apm-20-2014). The authors have no conflicts of interest to declare.

Ethical Statement: The authors are accountable for all aspects of the work in ensuring that questions related to the accuracy or integrity of any part of the work are appropriately investigated and resolved. Oral consent was obtained from patients or patients' relatives. Informed consents were obtained for all involved subjects in accordance with the Institutional Review Board (IRB) of the First Affiliated Hospital of Xi'an Jiaotong University (No: XJTU1AF2021LSK-037). The study conformed to the provisions of the Declaration of Helsinki (as revised in 2013).

Open Access Statement: This is an Open Access article distributed in accordance with the Creative Commons Attribution-NonCommercial-NoDerivs 4.0 International License (CC BY-NC-ND 4.0), which permits the noncommercial replication and distribution of the article with the strict proviso that no changes or edits are made and the original work is properly cited (including links to both the formal publication through the relevant DOI and the license). See: https://creativecommons.org/licenses/by-nc-nd/4.0/.

\section{References}

1. Huang C, Wang Y, Li X, et al. Clinical features of patients infected with 2019 novel coronavirus in Wuhan, China. Lancet 2020;395:497-506.

2. World Health Organization Coronavirus Disease (COVID-19) Dashboard. Available online: https://covid19. who.int/. Accessed 7 July 2020.

3. Chen N, Zhou M, Dong X, et al. Epidemiological and clinical characteristics of 99 cases of 2019 novel coronavirus pneumonia in Wuhan, China: a descriptive study. Lancet 2020;395:507-13.

4. Xu Z, Shi L, Wang Y, et al. Pathological findings of COVID-19 associated with acute respiratory distress syndrome. Lancet Respir Med 2020;8:420-2.

5. Wang D, Yin Y, Hu C, et al. Clinical course and outcome of 107 patients infected with the novel coronavirus, SARSCoV-2, discharged from two hospitals in Wuhan, China. Crit Care 2020;24:188.

6. Diagnosis and Treatment Guideline for Novel Coronavirus Pneumonia (Trial 7th Edition). The People's Republic of China: National Health Commission of the People's Republic of China, General Office of the National Health
Commission.

7. Puhan MA, Gimeno-Santos E, Cates CJ, et al. Pulmonary rehabilitation following exacerbations of chronic obstructive pulmonary disease. Cochrane Database Syst Rev 2016;12:CD005305.

8. Salhi B, Troosters T, Behaegel M, et al. Effects of pulmonary rehabilitation in patients with restrictive lung diseases. Chest 2010;137:273-9.

9. Bolton CE, Bevan-Smith EF, Blakey JD, et al. British Thoracic Society guideline on pulmonary rehabilitation in adults. Thorax 2013;68 Suppl 2:ii1-30.

10. Spruit MA, Singh SJ, Garvey C, et al. An official American Thoracic Society/European Respiratory Society statement: key concepts and advances in pulmonary rehabilitation. Am J Respir Crit Care Med 2013;188:e13-64.

11. Lau HM, Ng GY, Jones AY, et al. A randomised controlled trial of the effectiveness of an exercise training program in patients recovering from severe acute respiratory syndrome. Aust J Physiother 2005;51:213-9.

12. Rodriguez-Morales AJ, Cardona-Ospina JA, GutiérrezOcampo E, et al. Clinical, laboratory and imaging features of COVID-19: A systematic review and meta-analysis. Travel Med Infect Dis 2020;34:101623.

13. Chinese Association of Rehabilitation Medicine; Respiratory Rehabilitation Committee of Chinese Association of Rehabilitation Medicine; Cardiopulmonary Rehabilitation Group of Chinese Society of Physical Medicine and Rehabilitation. Recommendations for respiratory rehabilitation of coronavirus disease 2019 in adult. Zhonghua Jie He He Hu Xi Za Zhi 2020;43:308-14.

14. Wang D, Hu B, Hu C, et al. Clinical Characteristics of 138 Hospitalized Patients With 2019 Novel CoronavirusInfected Pneumonia in Wuhan, China. JAMA 2020;323:1061-9.

15. Cao B, Wang Y, Wen D, et al. A Trial of LopinavirRitonavir in Adults Hospitalized with Severe Covid-19. N Engl J Med 2020;382:1787-99.

16. Liu K, Zhang W, Yang Y, et al. Respiratory rehabilitation in elderly patients with COVID-19: A randomized controlled study. Complement Ther Clin Pract 2020;39:101166.

17. Basso-Vanelli RP, Di Lorenzo VA, Labadessa IG, et al. Effects of Inspiratory Muscle Training and Calisthenicsand-Breathing Exercises in COPD With and Without Respiratory Muscle Weakness. Respir Care 2016;61:50-60.

18. Raghu G, Collard HR, Egan JJ, et al. An official ATS/ ERS/JRS/ALAT statement: idiopathic pulmonary fibrosis: evidence-based guidelines for diagnosis and management. 
Am J Respir Crit Care Med 2011;183:788-824.

19. Renjun G, Ziyun L, Xiwu Y, et al. Psychological intervention on COVID-19: A protocol for systematic review and meta-analysis. Medicine 2020;99:e20335.

20. Casanova C, Marin JM, Martinez-Gonzalez C, et al. Differential Effect of Modified Medical Research Council Dyspnea, COPD Assessment Test, and Clinical COPD Questionnaire for Symptoms Evaluation Within the New GOLD Staging and Mortality in COPD. Chest 2015;148:159-68.

21. Woods EC, O'Conor R, Martynenko M, et al. Associations Between Asthma Control and Airway Obstruction and Performance of Activities of Daily Living in Older Adults with Asthma. J Am Geriatr Soc 2016;64:1046-53.

22. Guan WJ, Ni ZY, Hu Y, et al. Clinical Characteristics of Coronavirus Disease 2019 in China. N Engl J Med 2020;382:1708-20.

23. Bordoni V, Sacchi A, Cimini E, et al. An inflammatory profile correlates with decreased frequency of cytotoxic cells in COVID-19. Clin Infect Dis 2020;71:2272-75.

24. Davidson WJ, Verity WS, Traves SL, et al. Effect of incremental exercise on airway and systemic inflammation in patients with COPD. J Appl Physiol (1985) 2012;112:2049-56.

25. do Nascimento ES, Sampaio LM, Peixoto-Souza FS, et al. Home-based pulmonary rehabilitation improves clinical features and systemic inflammation in chronic obstructive pulmonary disease patients. Int J Chron Obstruct Pulmon Dis 2015;10:645-53.

26. Suzuki K, Yamada M, Kurakake S, et al. Circulating cytokines and hormones with immunosuppressive but neutrophil-priming potentials rise after endurance exercise in humans. Eur J Appl Physiol 2000;81:281-7.

27. Mo X, Jian W, Su Z, et al. Abnormal pulmonary function

Cite this article as: Sun J, Liu J, Li H, Shang C, Li T, Ji W, Wu J, Han X, Shi Z. Pulmonary rehabilitation focusing on the regulation of respiratory movement can improve prognosis of severe patients with COVID-19. Ann Palliat Med 2021;10(4):42624272. doi: 10.21037/apm-20-2014 in COVID-19 patients at time of hospital discharge. Eur Respir J 2020;55:2001217.

28. Sonnweber T, Sahanic S, Pizzini A, et al. Cardiopulmonary recovery after COVID-19 - an observational prospective multi-center trial. Eur Respir J 2020. [Epub ahead of print]. doi: 10.1183/13993003.03481-2020.

29. Ngai JC, Ko FW, Ng SS, et al. The long-term impact of severe acute respiratory syndrome on pulmonary function, exercise capacity and health status. Respirology 2010;15:543-50.

30. Casaburi R, Bhasin S, Cosentino L, et al. Effects of testosterone and resistance training in men with chronic obstructive pulmonary disease. Am J Respir Crit Care Med 2004; 170:870-8.

31. Cutaia M, Brehm R, Cohen M. The relationship of the BODE index to oxygen saturation during daily activities in patients with chronic obstructive pulmonary disease. Lung 2011;189:269-77.

32. Zha L, Xu X, Wang D, et al. Modified rehabilitation exercises for mild cases of COVID-19. Ann Palliat Med 2020;9:3100-6.

33. Abdullahi A. Safety and Efficacy of Chest Physiotherapy in Patients With COVID-19: A Critical Review. Front Med (Lausanne) 2020;7:454.

34. López-López L, Torres-Sánchez I, Rodríguez-Torres $\mathrm{J}$, et al. Does adding an integrated physical therapy and neuromuscular electrical stimulation therapy to standard rehabilitation improve functional outcome in elderly patients with pneumonia? A randomised controlled trial. Clin Rehabil 2019;33:1757-66.

35. Guo Q, Zheng Y, Shi J, et al. Immediate psychological distress in quarantined patients with COVID-19 and its association with peripheral inflammation: A mixed-method study. Brain Behav Immun 2020;88:17-27. 